\title{
An Autoantibody Based Protein Microarray Blood Test to Enhance the Specificity of a Negative Screening Mammogram
}

\author{
T. M. Allweis ${ }^{*}$, L. Strauss ${ }^{2}$, Z. Malyutin², A. Bassein Kapov-Kagan², I. Novikov², \\ T. B. Bevers ${ }^{3}$, S. Iacobelli ${ }^{4}$, M. T. Sandri' ${ }^{5}$, A. Bitterman', P. Engelman ${ }^{7}$, \\ B. Piura ${ }^{2}$, M. Rosenberg ${ }^{8}$, G. Yahalom ${ }^{*} \#$ \\ ${ }^{1}$ Kaplan Medical Center, Rehovot, Israel \\ ${ }^{2}$ Eventus Diagnostics (Israel) LTD, Ora, Israel \\ ${ }^{3}$ University of Texas, MD Anderson Cancer Center, Houston, USA \\ ${ }^{4}$ Media Pharma Srl, Chieti, Italy \\ ${ }^{5}$ Laboratory Medicine Division, Istituto Europeo di Oncologia, Milan, Italy \\ ${ }^{6}$ Carmel Medical Center, Surgery A, Haifa, Israel \\ ${ }^{7}$ Zvulun Breast Center, Clalit Organization, Kiryat Bialik, Israel \\ ${ }^{8}$ Eventus Diagnostics Inc., Miami, USA \\ Email: "galit@eventusdx.com
}

Received 2 January 2015; accepted 19 January 2015; published 22 January 2015

Academic Editor: Yu Cao, The Scripps Research Institute, USA

Copyright (C) 2015 by authors and Scientific Research Publishing Inc.

This work is licensed under the Creative Commons Attribution International License (CC BY).

http://creativecommons.org/licenses/by/4.0/

c) (i) Open Access

\begin{abstract}
Background: Current screening mammography for breast cancer is associated with misdiagnosis in as many as $30 \%$ of cases. Objectives: To develop and clinically evaluate a unique autoantibody based protein microarray blood test to improve the accuracy of breast cancer screening. Materials and Methods: A microarray was constructed from commercial antigens and antigens selected from screened cDNA libraries of breast cancer tissue samples. A training set containing 439 healthy controls and 276 biopsy proven breast cancer cases was used to establish a set of separating models between the two groups. These models were used to assign a diagnosis to 285 blind samples from 120 breast cancer patients and 165 healthy controls. Results: The test identified 82 of the 120 breast cancer patients and 160 of the 165 healthy controls. These results can be translated into a sensitivity of $68.3 \%$ [CI: $59 \%-77 \%$ ] and a specificity of $97 \%$ [CI: $93 \%-99 \%$ ], with a PPV for this validation set of $94.3 \%$ (CI: $87.10 \%-98.11 \%$ ), NPV of $80.81 \%$ [CI: $74.62 \%-86.05 \%$ ] and an AUC of
\end{abstract}

\footnotetext{
Equally contributed.

${ }^{\#}$ Corresponding author.
}

How to cite this paper: Allweis, T.M., et al. (2015) An Autoantibody Based Protein Microarray Blood Test to Enhance the Specificity of a Negative Screening Mammogram. Advances in Breast Cancer Research, 4, 22-38. 
89.2\% [CI: 78\% - 87\%]. Conclusions: The protein microarray can be utilized to reduce the false negative rate of routine screening mammography. Women with a negative mammography and a negative blood test can be reassured and encouraged to continue routine breast cancer screening. A positive test should alert the physician about the possible presence of a breast cancer not detected by routine screening mammography and drive to perform additional investigation, such as breast ultrasound and MRI.

\section{Keywords}

Autoantibodies, Breast Cancer, Diagnostic, Screening

\section{Introduction}

Worldwide, breast cancer is the most common cancer and the most common cause of death from cancers among women. Lifetime incidence of breast cancer is reported by the American Cancer Society to be between $12 \%$ and $13 \%$ in the US, with similar rates in the western world [1]. Imaging modalities for breast cancer detection include mammography, ultrasound (US) and magnetic resonance imaging (MRI). However, the mainstay of screening for breast cancer is mammography which is currently the only recommended screening modality for women over 40 - 50 years of age in much of the developed world [2]. The issue of recommended mammography is specifically challenged in the subpopulation of women with dense breast tissue. While mammography has an overall sensitivity of $50 \%-70 \%$ [3], in younger women and in women with dense breast tissue the sensitivity is greatly reduced [4]. Approximately $50 \%$ of women have dense breasts $(50 \%$ or more of breast volume occupied by fibroglandular tissue on mammography) on initial screening mammography. It has been demonstrated that women with dense breast are at higher risk of developing breast cancer, as well as at greater risk of missing a tumor on mammography due to masking by fibroglandular tissue [5] [6]. Thus, it has been suggested that women with dense breasts and a negative screening mammography undergo further supplemental imaging such as breast ultrasound and/or breast MRI.

An American College of Radiology Imaging Network (ACRIN) study comparing mammography alone to mammography with the addition of ultrasound in women with dense breast showed a breast cancer detection rate of 7.6 cancers per 1000 women screened with mammography alone versus 11.8 cancers detected per 1000 women screened with the combination of mammography and ultrasound [4] [7]. Other studies showed an improved cancer detection rate for women with dense breast from $0.25 \%$ to $0.46 \%$ [6] or by $20 \%$ [8]. The majority of cancers detected solely by supplemental ultrasound were node-negative invasive carcinomas, corresponding to a lower stage and allowing the possibility of earlier treatment and improved survival. However, a decrease in specificity by $7 \%$ with the combination of mammography and ultrasound versus mammography alone was reported as well. Although the increase in cancer detection rate of mammography combined with ultrasound may be beneficial, the increased biopsy rate, especially of unnecessary biopsies, results in increased morbidity [4] [7]. MRI is another imaging method proposed to improve screening. The lack of ionizing radiation and the fact that it is not affected by breast tissue density makes it a promising option. Many studies have shown increased breast cancer detection rates with MRI after a negative mammography in women with an elevated risk for breast cancer [9]-[11]. The ACRIN 6666 investigators demonstrated that an additional 14.7 cancers were detected per 1000 women screened using MRI after mammography [2] [4] [7]. Nevertheless, MRI also showed a high false-positive rate: 7\% of women in the ACRIN 6666 study underwent biopsy on the basis of MRI findings alone, but only $18.6 \%$ of them were found to have breast cancer [4]. High false-positive rates ultimately increase patient morbidity without improving mortality. Furthermore, MRI is generally less well tolerated by patients than ultrasound. The high cost and need for injection of contrast material also make MRI a less attractive technique for widespread screening except in very high risk patients such a BRCA mutation carriers [5].

The drawbacks of current breast cancer screening modalities support the general consensus among breast cancer surgeons and the public where there is an urgent and unmet need to develop more accurate, non-invasive, simple and low risk additions or alternatives for screening and early diagnosis of breast cancer [12]. The immune system as a potential tool to help in diagnosis of cancer has been challenged many times for many differ- 
ent cancers. Thus far, only a small number of circulating autoantibodies specific to breast carcinoma antigens have been identified and investigated [13]. The best known are Her2 [14] and Muc1 [15], both of which can be over expressed in breast tumors, and are involved in the production of specific autoantibodies. So far, current efforts to predict or diagnose breast cancer based on autoimmunity have not resulted in clinically applicable serologic biomarkers with accurate and definitive predictive and diagnostic capabilities. There are several explanations for this phenomenon. First, most of the autoantibodies against cancer cells are present in high enough levels (3SD above background) in only a small proportion of cancer patients, as well as in a similar proportion of healthy individuals [16]-[19]. Second, some antibodies tend to appear in several types of cancer, and thus lack the sensitivity needed [17] [19]. Lastly, some antibodies appear in disease states other than cancers [16] [20] [21]. These facts led to the hypothesis that a panel of autoantibodies, rather than a single antibody, would be much more helpful in the diagnosis of cancer by this method [19] [22]-[25].

We have recently reported that an autoantibody panel has the potential to serve as an additional tool for breast cancer diagnosis [26]. In this previous report, a panel of 15 antigens was used to develop a highly sensitive blood test. This tool can be especially helpful for the sub-population of women with dense breast, in whom mammography loses much of its sensitivity. In order to utilize such a blood test for women after negative mammography, a test with high specificity is needed. High specificity will assure a low rate of false positive results, which are the major cause for unnecessary procedures. In this report, we described the development and performance of a microarray based on antigens that were derived from cDNA libraries. The unique microarray was developed using a set of 715 known plasma samples, and tuned to achieve high specificity. After establishing algorithms based on these known plasma samples, the microarray was tested on a set of 285 blind plasma samples in order to estimate its sensitivity and specificity.

\section{Materials and Methods}

Study design All participants were female subjects over the age of 18 with a breast abnormality detected by clinical breast examination, mammogram, ultrasound, or breast MRI, and women presenting for routine screening with a negative mammography (BIRADS 1,2). All women who had an indeterminate/suspicious abnormality underwent a pathological diagnosis by core needle or surgical biopsy of the lesion. Those with pathologically proven breast cancer (invasive ductal, invasive lobular and ductal carcinoma in situ) were considered as "cases", and those with negative mammography and/or benign biopsy result (fibroademoas, fibrocystic changes including ADH, ALH and LCIS) were "controls". Although both DCIS and ADH are similar entities with the diagnosis being a quantitative difference in the atypical cells present on the biopsy, biologically, there may not be significant differences between the two, which should be further explored in future studies, the reason for this difference lies within the different treatment given to each group. In situations where there was a discrepancy between the results of the needle biopsy and surgery, the pathologic findings at surgery overruled the needle biopsy results. Patients with biopsy samples with no pathological report, or with no final diagnosis, were excluded from the study. Women were not eligible to participate if they had a previous or concurrent malignancy including hematologic malignancies, were receiving chemotherapy, or had chemotherapy or steroid-based therapy in the past 6 months. Women undergoing immunosuppressive treatments or women with an autoimmune disorder were also excluded. The study in the different centers was conducted under local Institutional Review Board (IRB) approvals (trial registration ID: NCT01343849), and subjected to signing informed consent by each participant. Data forms were completed by each site to obtain clinical information and final pathological diagnosis.

Blood samples collection Plasma was collected from whole blood using heparin tubes (Greiner Cat. No. 455084) centrifuged at $4000 \mathrm{RPM}$ for $10 \mathrm{~min}$ at room temperature and aliquots were stored frozen at $-80^{\circ} \mathrm{C}$ until microarray analysis.

cDNA libraries construction Four breast cancer tissues were used to construct a cDNA library. All tissues were originated from invasive ductal carcinoma. Two were triple positive (ER, PR, Her2), one was ER positive and the forth was Her2 positive. In short, RNA was extracted using NucleoSpin ${ }^{\circledR}$ RNA (Macherey-Nagel Cat. No. 740955.10) extraction kit according to manufacturer instructions. Using In-Fusion ${ }^{\circledR}$ SMARTer Directional cDNA Library Construction Kit (Clonetech Cat. No. 634933) a library of at least 1E6 different clones was constructed from each tissue.

Screening for reactive antigens Clones from 4 different cDNA libraries were produced using auto-induction protocol and purified using Hispur Ni-ANT resin (Pierce, Cat. No. 88221). Individual clones were picked, 
and arrayed on NEXTERION® Slide E (Schott Cat. No. 1066643) using a Micro Grid II microarrayer (Digilab) with split pins. Protein microarrays were blocked using Blockit plus (Arrayit, Cat. No. BKTPL) for 1 hour at room temperature followed by 1 hour incubation with human plasma samples diluted 1:100 in blocking buffer. After 1 hour incubation at $37^{\circ} \mathrm{C}$ with gentle agitation, microarrays were washed 3 times with $0.1 \%$ PBST followed by 3 washes with PBS. 1:500 Goat-anti-Human-Cy3 conjugated (Jackson Immuno Research, Cat. No. 109-165-003) was added for $30 \mathrm{~min}$ at $37^{\circ} \mathrm{C}$ with gentle agitation, followed by same washing procedures.

Data acquisition and analysis Microarrays were scanned with Innoscan710 scanner (Innopsys) at $532 \mathrm{~nm}$, and quantified using Mapix software. In the first round of selection, each antigen was screened against 70 plasma samples (35 breast cancer cases and 35 controls) and evaluated by their t-test. In addition, each clone was used individually to derive a receiver operating characteristic (ROC) curve that was ranked according to the area under curve produced for each antigen. Antigens with t-test statistic $t>2$ or area under curve (AUC) above 0.6 were chosen for the second round of selection - screening against plasma from 150 breast cancer cases and 150 controls. The same acceptance criteria were applied to the antigens in the second round. The second round of selection resulted with the 39 antigens that were printed on the protein microarray slides in order to evaluate their performance on blind samples.

Protein microarray printing All antigens were diluted to a printing concentration of $(0.1-1 \mathrm{mg} / \mathrm{ml})$ in a 384 well plates (Arrayit Cat. No. MMP384), and arrayed on NEXTERION® Slide E (Schott cat. No. 1066643) using a Micro Grid II microarrayer (Digilab) with split pins. The slides were blocked using Blockit plus (Arrayit, Cat. No. BKTPL) for 1 hour at room temperature, and stored at $4^{\circ} \mathrm{C}$ under vacuum until use.

Protein microarray slide development Samples were defrosted and loaded on an MF membrane (GE healthcare Cat. No. MF1 8122-2250) for a period of 24 hours at room temperature followed by extraction with reaction buffer (Arrayit, Cat. No. PMRB), and loaded on the protein microarrays in dilutions of 1:10 - 1:20. After 1 hour incubation at $37^{\circ} \mathrm{C}$ with gentle agitation, microarrays were washed 3 times with $0.1 \%$ PBST followed by 3 washes with PBS. 1:500 Goat-anti-Human-Cy3 conjugated (Jackson Immuno Research, Cat. No. 109165003) was added for 30 minutes at $37^{\circ} \mathrm{C}$ with gentle agitation, followed by same washing procedures. Microarrays were scanned with Innoscan710 scanner (Innopsys) at $532 \mathrm{~nm}$, and quantified using Mapix software.

Protein microarray data analysis The samples were randomly divided into two groups, 715 samples were designated as the training set, and the remaining 285 samples as blind samples. The results obtained from the 57 antigens were $\log$ transformed and normalized to the median of each sample. The results of the samples in the training set were applied to the IBM SPSS modeler that produced separating models based on machine learning algorithms (Neural Network, Chaid, CRT and C5). These models were applied to the blind set sample data, and resulted with a score of " 0 " or " 1 " for each sample. The score was compared to the clinical status that was obtained for each sample to calculate sensitivity, specificity, NPV and PPV.

\section{Results}

Study participants A total of 1000 plasma samples were obtained from five centers. The samples tested in this study were randomly divided into two groups (training set and blind validation set), with similar average age distribution of breast cancer cases and controls between the two groups (see Table 1).

Of the 1000 samples collected, 604 were controls (either with negative mammography or negative/benign biopsy results) and 396 were cases (327 invasive ductal breast cancer, 25 had invasive lobular breast cancer and 44 had ductal carcinoma in situ) (see Figure 1).

Library construction Four different cDNA libraries were constructed from 4 different invasive ductal breast cancer tissue samples (two triple positive IDC, one Her2 positive ER/PR negative and one ER positive). Each library contained at least 1E6 clones. The cDNA libraries were pooled and screened for reactive antigens.

High throughput protein microarray screening for selection of reactive antigens A total of 119,808 clones were randomly selected from the pool libraries. These clones were printed on microarrays and screened in two rounds of selection. The first round consisted of 70 plasma samples ( 35 breast cancer cases and 35 controls), and the second round of selection consisted of 150 breast cancer cases and 150 controls. Each antigen received a score based upon t-test and AUC (see materials and methods). In order to pass a selection round, a potential antigen had to have either t-test $>2$ or AUC $>0.6$. The average t-test was 2.7 for antigens being selected at the first round and 3.4 for those being selected at the second round. The average AUC was 0.7 for the first selection round and 0.64 for the second round. A total of 39 antigens passed at least one of the criteria in the second selection round (see supplementary data in Table S1). 
Table 1. Age information of subjects participating in the study divided to controls and breast cancer cases in the training set and the blind validation set.

\begin{tabular}{|c|c|c|c|}
\hline & & Controls & Breast cancer cases \\
\hline \multirow{3}{*}{ Training set } & mean (age) \pm sd. & $48.8 \pm 14.5$ & $58.8 \pm 12.9$ \\
\hline & range & $18-81$ & $32-91$ \\
\hline & $\%$ above 50 & $51 \%$ & $74 \%$ \\
\hline \multirow{3}{*}{ Blind validation set } & mean (age) $\pm \mathrm{sd}$ & $49.0 \pm 14.0$ & $60.5 \pm 13.3$ \\
\hline & range & $20-82$ & $31-93$ \\
\hline & $\%$ above 50 & $53 \%$ & $81 \%$ \\
\hline
\end{tabular}

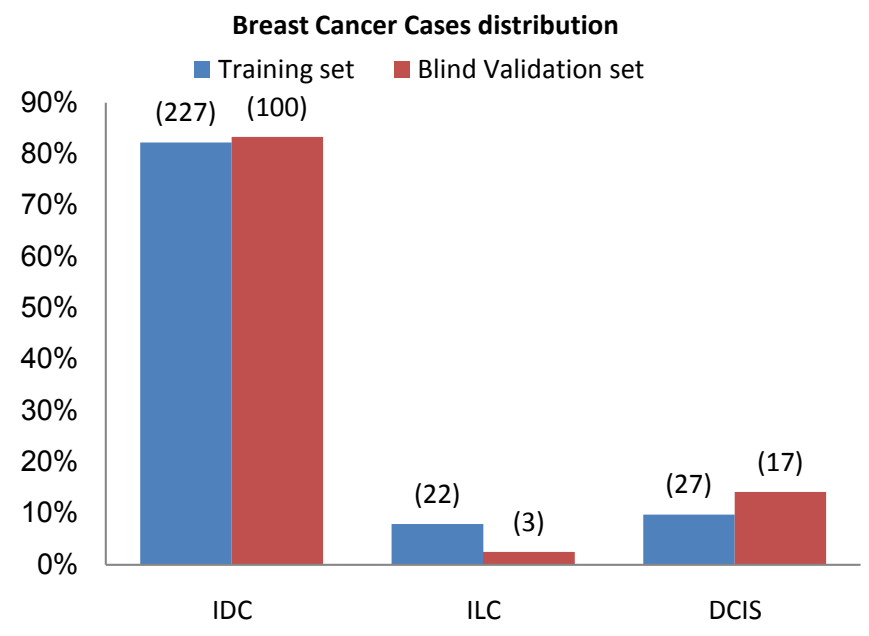

Figure 1. Percentage distribution of breast cancer cases (according to diagnosis) in the training and blind validation sets.

Microarray construction A total of 39 antigens derived from the cDNA libraries which showed the best separation probability together with 17 commercial antigens, all reported to be associated with a humoral response in breast cancer, were printed on epoxy slides (a total of 56 antigens examined). Of the 17 commercial antigens used, 15 were previously reported as highly sensitive in predicting the presence of breast cancer as a part of a panel of antigens [26]. The commercial antigens used are summarized in Table 2.

Protein microarray performances In order to evaluate the performance of the protein microarray, a total of 1000 plasma samples were used (one sample per a participant). All samples were tested on the protein microarray using the same protocol (see materials and methods). The samples were divided into two groups - a total of 715 were a part of the training set that was used to develop a set of prediction models, upon which the remaining 285 blinded samples (blind validation set) were tested and given a predicted clinical status.

Prediction using the Protein microarray The training set containing serum from 439 controls (negative mammography or benign lesions) and 276 breast cancer cases was used to establish the mathematical algorithms. After processing the samples, each sample, with a known clinical status, received a set of values, one per each antigen, which corresponded to the relative amount of each autoantibody (see materials and methods). These values were used to establish the separating algorithm between the breast cancer patients and the healthy controls. The algorithm was tuned to achieve at least $95 \%$ specificity and at least $50 \%$ sensitivity.

The remaining 285 blinded samples were then tested, and received a score of either " 0 " (control) or "1" (case) based on the algorithm (see supplementary Table S2). The results were compared to the clinical data in order to evaluate the sensitivity and specificity of the test. A total of 82 (out of the 120) breast cancer cases were diagnosed correctly translating to a sensitivity of $68.3 \%$ (CI: $59.2 \%-76.5 \%$ ). A total of 160 (out of 165) controls were diagnosed correctly translating to a specificity of $96.97 \%$ (CI: $93.1 \%-99.0 \%$ ), see Table 3 . The NPV for this validation set was $80.8 \%$ (CI: $74.6 \%$ - 86.1\%) and PPV for this validation set was $94.3 \%$ (CI: $87.1 \%-98.1 \%$ ). The overall AUC obtained for this set was 89.2\% (CI: 78\% - 87\%), as seen in the ROC analysis in Figure 2. 
Table 2. List of commercial antigens used on the microarray construction.

\begin{tabular}{lccc}
\hline No. & Sequence & Origin & reference \\
\hline Ag1 & QRASPLTSIISAVVGI & ErbB-2 & {$[14]$} \\
Ag2 & TAPLQPEQLQVFETLEEI & ErbB-2 & {$[14]$} \\
Ag3 & NGTSFDIHYGSGSLSGYLS & Cathepsin D & {$[29]$} \\
Ag4 & HSP27 & HSP27 & {$[38]$} \\
Ag5 & EPLSQETFSDLWKLLPENNVLSPL & p53 & {$[30]$} \\
Ag6 & DDLMLSPDDIEQWFTEDPGP & p53 & {$[31]$} \\
Ag7 & NHEPSVTQVILDRPY & Phage display & {$[32]$} \\
Ag8 & HoxB7 & HoxB7 & {$[33]$} \\
Ag9 & LGALS3BP & LGALS3BP & {$[34]$} \\
Ag10 & GIPC & GIPC & {$[14]$} \\
Ag11 & TFETLEEITGYLYISAWPD & her2 & {$[35]$} \\
Ag12 & TPO & TPO & {$[29]$} \\
Ag13 & Cathepsin D & Cathepsin D & {$[36]$} \\
Ag14 & p53 & p53 & {$[29]$} \\
Ag15 & ErbB-2 & chd1 & {$[14]$} \\
Ag16 & CEA & ErbB-2 & CEA \\
Ag17 & & & {$[37]$} \\
\hline
\end{tabular}

Table 3. Prediction on a blind set of 285 samples using mathematical algorithm based on protein microarrays results.

\begin{tabular}{|c|c|c|c|}
\hline & Clinical status & Controls & Cases \\
\hline \multicolumn{4}{|c|}{ Protein microarray results } \\
\hline negative & & 160 & 38 \\
\hline \multirow[t]{5}{*}{ positive } & & 5 & 82 \\
\hline & & Specificity & Sensitivity \\
\hline & & $97 \%$ & $68 \%$ \\
\hline & & NPV & PPV \\
\hline & & $81 \%$ & $94 \%$ \\
\hline
\end{tabular}

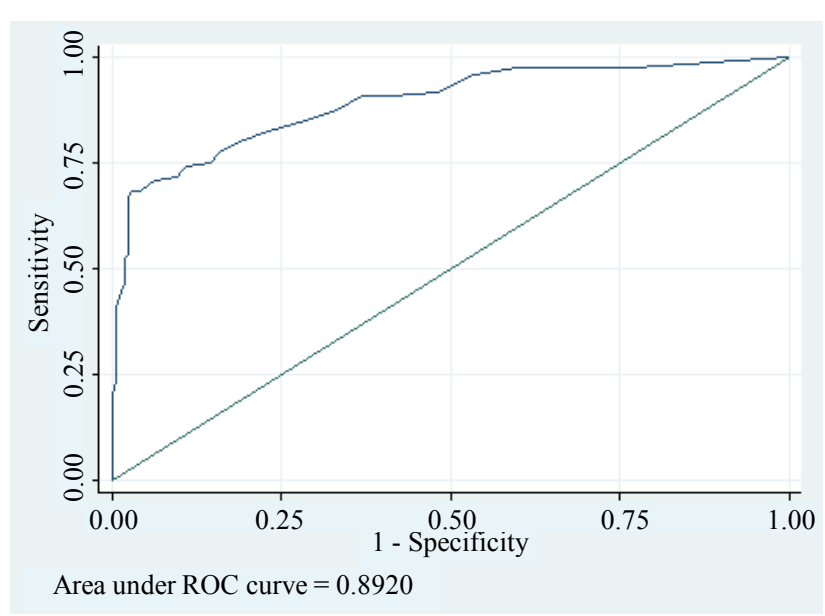

Figure 2. ROC for the prediction set of 285 blind samples. An AUC of $89.2 \%$ was achieved, representing $97 \%$ specificity and $68 \%$ sensitivity. 


\section{Discussion}

Screening mammography as a standalone modality for the early detection of breast cancer has several limitations, especially in women with dense breasts. Here, we demonstrated that this newly developed blood test based on a panel of antigen selectively chosen to recognize breast cancer autoantibodies has a high specificity (97\%) with a moderate sensitivity (68\%), and an AUC of $89 \%$ for breast cancer detection. These results compare favorably with screening mammography as a standard standalone test whose sensitivity is $70 \%-80 \%$ (range: $29 \%$ - 97\%) [27] and specificity $35 \%$ - 98\% [28].

Because of these characteristics (high specificity and moderate sensitivity), the new test can be used as a second line screening for women with negative mammography. Particularly, in this sub-population, $68 \%$ of the undiagnosed women can be detected with the autoantibody-based blood test at the cost of $3 \%$ false positive results. Patients displaying positive results should be referred to additional and more sensitive imaging modalities (such as US or MRI). The benefit of utilizing this blood test prior to other imaging modalities lies in the possibility to reduce many false positive results of the other modalities that will occur if the test is not performed prior to MRI.

Some patients' sub-populations, specifically women with dense breast tissue, in whom mammography is highly inaccurate, may benefit more from using a blood test. After receiving a negative mammography result, these women can undergo a blood test that will refer them to additional and more sensitive imaging techniques. To this end, additional clinical studies should be performed in order to evaluate the sensitivity and specificity of the autoantibody based blood test, specifically for the dense breast sub-population.

Breast imaging, either anatomical or functional, is limited by many factors. Tumor antigenicity as a tool for breast cancer detection is only beginning to be explored, but shows a promise in taking cancer screening to a biological era.

\section{Acknowledgements}

The authors greatly appreciate the cooperation and efforts of M.D. Anderson Cancer Center, University G. D’Annunzio, Division of Senology, European Institute of Oncology, Carmel Medical Center Zvulun Breast Center and Kaplan Medical Center, who have generously provided all the specimens for this study. We also thank M.D. Anderson's research personnel Diane M Weber (RN, BSN) and Valerie O Sepeda (RN, BSN), for help in obtaining the breast cancer samples used in this study. In addition we would like to thank Sarah (Luna) Cohen (CRA), Svetlana Rothe (CRA), Ortal Karazi and Eva Yadin for their extensive labor. The authors would like to acknowledge the huge contribution of the late Prof. Donny Strosberg for his scientific involvement in this project.

\section{References}

[1] IARC (2012) IARC [Online]. http://globocan.iarc.fr/Pages/fact sheets_population.aspx

[2] D’Orsi, C.J. and Newell, M.S. (2011) On the Frontline of Screening for Breast Cancer. Seminars in Oncology, 38, 119127. http://dx.doi.org/10.1053/j.seminoncol.2010.11.004

[3] Pisano, E.D., et al. (2005) Diagnostic Performance of Digital versus Film Mammography for Breast-Cancer Screening. The New England Journal of Medicine, 353, 1773-1783. http://dx.doi.org/10.1056/NEJMoa052911

[4] Berg, W.A., et al. (2012) Detection of Breast Cancer with Addition of Annual Screening Ultrasound or a Single Screening MRI to Mammography in Women with Elevated Breast Cancer Risk. The Journal of the American Medicine Association, 307, 1394-1404. http://dx.doi.org/10.1001/jama.2012.388.

[5] Ho, J.M., Jafferjee, N., Covarrubias, G.M., Ghesani, M. and Handler, B. (2014) Dense Breasts: A Review of Reporting Legislation and Available Supplemental Screening Options. American Journal of Roentgenology, 203, 449-456. http://dx.doi.org/10.2214/AJR.13.11969.

[6] Crystal, P., Strano, S.D., Shcharynski, S. and Koretz, M.J. (2003) Using Sonography to Screen Women with Mammographically Dense Breasts. American Journal of Roentgenology, 181, 177-182. http://dx.doi.org/10.2214/ajr.181.1.1810177.

[7] Berg, W.A., et al. (2008) Combined Screening with Ultrasound and Mammography vs. Mammography Alone in Women at Elevated Risk of Breast Cancer. The Journal of the American Medicine Association, 299, 2151-2163. http://dx.doi.org/10.2214/ajr.181.1.1810177.

[8] Kolb, T.M., Lichy, J. and Newhouse, J.H. (2002) Comparison of the Performance of Screening Mammography, Physical Examination, and Breast US and Evaluation of Factors that Influence Them: An Analysis of 27,825 Patient Evalua- 
tion. Radiology, 225, 165-175. http://dx.doi.org/10.1148/radiol.2251011667.

[9] Kuhl, C.K., et al. (2005) Mammography, Breast Ultrasound, and Magnetic Resonance Imaging for Surveillance of Women at High Familial Risk for Breast Cancer. Journal of Clinical Oncology, 23, 8469-8476. http://dx.doi.org/10.1200/JCO.2004.00.4960.

[10] Lehman, C.D., et al. (2007) Cancer Yield of Mammography, MR, and US in High-Risk Women. Radiology, 244, 381388. http://dx.doi.org/10.1148/radiol.2442060461.

[11] Warner, E., Plewes, D.B., Shumak, R.S., Catzavelos, G.C., Di Prospero, L.S., Yaffe, M.J., et al. (2001) Comparison of Breast Magnetic Resonance Imaging, Mammography, and Ultrasound for Surveillance of Women at High Risk for Hereditary Breast Cancer. Journal of Clinical Oncology, 19, 3524-3531.

[12] Weigelt, B., Geyer, F.C. and Reis-Filho, J.S. (2010) Histological Types of Breast Cancer: How Special Are They? Molecular Oncology, 4, 192-208. http://dx.doi.org/10.1016/j.molonc.2010.04.004

[13] Piura, E. and Piura, B. (2010) Autoantibodies to Tummor-Associated Antigens in Breast Carcinoma. Journal of Oncology, 2010, Article ID: 264926.

[14] Baselga, J., Seidman, A.D., Norton, L. and Rosen, P.P. (1997) HER2 Overexpression and Paclitaxel Sensitivity in Breast Cancer: Therapeutic Implications. Oncology, 11, 43-48.

[15] Yang, E., Hu, X.F. and Xing, P.X. (2007) Advances of MUC1 as a Target for Breast Cancer Immunotherapy. Histology and Histopathology, 22, 905-922.

[16] Daniels, T., Zhang, J.Y., Gutierrez, I., Elliot, M.L., Yamada, B., Jo Heeb, M., et al. (2005) Antinuclear Autoantibodies in Prostate Cancer: Immunity to LEDGF/p75, a Survival Protein Highly Expressed in Prostate Tumors and Cleaved during Apoptosis. The Prostate, 62, 14-26. http://dx.doi.org/10.1002/pros.20112

[17] Soussi, T. (2000) p53 Antibodies in the Sera of Patients with Various Types of Cancer: A Review. Cancer Research, 60, 1777-1788.

[18] Rohayem, J., Diestelkoetter, P., Weigle, B., Oehmichen, A., Schmitz, M., Mehlhorn, J., Conrad, K., Rieber, E.P., et al. (2000) Antibody Response to the Tumor-Associated Inhibitor of Apoptosis Protein Survivin in Cancer Patients. Cancer Research, 60, 1815-1817.

[19] Zhang, J.Y., Casiano, C.A., Peng, X.X., Koziol, J.A., Chan, E.K. and Tan, E.M. (2003) Enhancement of Antibody Detection in Cancer Using Panel of Recombinant Tumor-Associated Antigens. Cancer Epidemiology, Biomarkers \& Prevention, 12, 136-143.

[20] Ganapathy, V., Daniels, T. and Casiano, C.A. (2003) LEDGF/p75: A Novel Nuclear Autoantigen at the Crossroads of Cell Survival and Apoptosis. Autoimmunity Reviews, 2, 290-297. http://dx.doi.org/10.1016/S1568-9972(03)00063-6

[21] Ganapathy, V. and Casiano, C.A. (2004) Autoimmunity to the Nuclear Autoantigen DFS70 (LEDGF): What Exactly Are the Autoantibodies Trying to Tell Us? Arthritis \& Rheumatism, 50, 684-688. http://dx.doi.org/10.1002/art.20095

[22] Ludwig, N., Keller, A., Comtesse, N., Rheinheimer, S., Pallasch, C., Fischer, U., et al. (2008) Pattern of Serum Autoantibodies Allows Accurate Distinction between a Tumor and Pathologies of the Same Organ. Clinical Cancer Research, 14, 4767-4774. http://dx.doi.org/10.1158/1078-0432.CCR-07-4715

[23] Leidinger, P., Keller, A., Ludwig, N., Rheinheimer, S., Hamacher, J., Huwer, H., et al. (2008) Towards an Early Diagnosis of Lung Cancer: An Autoantibody Signature for Squamous Cell Lung Carcinoma. International Journal of Cancer, 123, 1631-1636. http://dx.doi.org/10.1002/ijc.23680

[24] Lin, H.S., Talwar, H.S., Tarca, A.L., Ionan, A., Chatterjee, M., Ye, B., et al. (2007) Autoantibody Approach for Serum Based Detection of Head and Neck Cancer. Cancer Epidemiology, Biomarkers \& Prevention, 16, 2396-2405. http://dx.doi.org/10.1158/1055-9965.EPI-07-0318

[25] Piura, E. and Piura, B. (2011) Autoantibodies to Tailor-Made Panels of Tumor Associated Antigens in Breast Carcinoma. Journal of Oncology, 2011, Article ID: 982425.

[26] Yahalom, G., Weiss, D., Novikov, I., Bevers, T.B., Radvanyi, L.G., Liu, M., et al. (2013) An Antibody-Based Blood Test Utilizing a Panel of Biomarkers as a New Method for Improved Breast Cancer Diagnosis. Biomarkers in Cancer, 5, 71-80. http://dx.doi.org/10.4137/BIC.S13236

[27] Smith-Bindman, R., Chu, P., Miglioretti, D.L., Quale, C., Rosenberg, R.D., Cutter, G., et al. (2005) Physician Predictors of Mammographic Accuracy. Journal of the National Cancer Institute, 97, 358-367. http://dx.doi.org/10.1093/jnci/dji060

[28] Beam, C.A., Conant, E.F., Sickles, E.A. and Weinstein, S.P. (2003) Evaluation of Proscriptive Health Care Policy Implementation in Screening Mammography. Radiology, 229, 534-540. http://dx.doi.org/10.1148/radiol.2292021585

[29] Chinni, S.R., Falchetto, R., Gercel-Taylor, C., Shabanowitz, J., Hunt, D.F. and Taylor, D.D. (1997) Humoral Immune Response to Cathepsin D and Glucose Regulated Protein 78 in Ovarian Cancer Patients. Clinical Cancer Research, 3, 1557-1564. 
[30] Lubin, R., Schlichtholz, B., Bengoufa, D., Zalcman, G., Trédaniel, J., Hirsch, A., et al. (1993) Analysis of p53 Antibodies in Patients with Various Cancers Define B-Cell Epitopes of Human p53: Distribution on Primary Structure and Exposure on Protein Surface. Cancer Research, 53, 5872-5876.

[31] Hansen, M.H., Nielsen, H. and Ditzel, H.J. (2001) The Tumor-Infiltrating B Cell Response in Medullary Breast Cancer Is Oligoclonal and Directed against the Autoantigen Actin Exposed on the Surface of Apoptotic Cancer Cells. Proceedings of the National Academy of Sciences of the United States of America, 98, 12659-12664. http://dx.doi.org/10.1073/pnas.171460798

[32] Erkanli, A.I., Taylor, D.D., Dean, D., Eksir, F., Egger, D., Geyer, J., et al. (2006) Application of Bayesian Modeling of Autologous Antibody Responses against Ovarian Tumor-Associated Antigens to Cancer Detection. Cancer Research, 66, 1792-1798. http://dx.doi.org/10.1158/0008-5472.CAN-05-0669

[33] Natoli, C., Iacobelli, S. and Kohn, L. (1996) The Immune Stimulatory Protein 90K Increases Major Histocompatibility Complex Class I Expression in a Human Breast Cancer Cell Line. Biochemical and Biophysical Research Communications, 225, 617-620. http://dx.doi.org/10.1006/bbrc.1996.1219

[34] Yavelsky, V., Rohkin, S., Shaco-Levy, R., Tzikinovsky, A., Amir, T., Kohn, H., et al. (2008) Native Human Autoantibodies Targeting GIPC1 Identify Differential Expression in Malignant Tumors of the Breast and Ovary. BMC Cancer, 8, 247-258. http://dx.doi.org/10.1186/1471-2407-8-247

[35] Smyth, P.P., Shering, S.G., Kilbane, M.T., Murray, M.J., McDermott, E.W., Smith, D.F., O’Higgins, N.J., et al. (1998) Serum Thyroid Peroxidase Autoantibodies, Thyroid Volume, and Outcome in Breast Carcinoma. Journal of Clinical Endocrinology and Metabolism, 83, 2711-2716.

[36] Nicolini, A., Capri, A. and Tarro, G. (2006) Biomolecular Markers of Breast Cancer. Frontiers in Bioscience, 11, 1818-1843. http://dx.doi.org/10.2741/1926

[37] Gold, P. and Freeman, S.O. (1965) Specific Carcino Embryonic Antigens of the Human Digestive System. Journal of Experimental Medicine, 122, 467-481. http://dx.doi.org/10.1084/jem.122.3.467

[38] Korneeva, I., Bongiovanni, A.M., Girotra, M., Caputo, T.A. and Witkin, S.S. (1999) Serum Antibodies to the 27-kd Heat Shock Protein in Women with Gynecologic Cancers. American Journal of Obstetrics and Gynecology, 183, 18-21. http://dx.doi.org/10.1016/S0002-9378(00)72431-8 
Table S1. T test auc of self antigens.

\begin{tabular}{|c|c|c|c|c|}
\hline $\mathrm{Ag} 1$ & $\mathrm{t}$ test (1) & Auc (1) & $\mathrm{t}$ test (2) & Auc (2) \\
\hline EBC01 & 2.19 & 0.61 & 2.47 & \\
\hline $\mathrm{EBC} 02$ & 2.58 & 0.64 & 2.96 & 0.61 \\
\hline $\mathrm{EBC} 03$ & 2.03 & 0.66 & 2.19 & \\
\hline EBC04 & 2.21 & 0.76 & 4.44 & 0.63 \\
\hline EBC05 & 2.33 & 0.61 & 2.63 & \\
\hline EBC06 & 2.93 & 0.7 & 3.91 & \\
\hline $\mathrm{EBC} 07$ & 2 & 0.67 & 3.28 & \\
\hline EBC08 & 2.8 & 0.77 & 4.32 & 0.62 \\
\hline EBC09 & 2.09 & 0.64 & 2.75 & \\
\hline EBC10 & & 0.69 & 3.6 & \\
\hline EBC11 & 3.54 & 0.79 & 3.24 & 0.61 \\
\hline $\mathrm{EBC} 12$ & 2.23 & 0.67 & 2.9 & 0.64 \\
\hline $\mathrm{EBC} 13$ & 2.41 & 0.64 & 2.51 & \\
\hline EBC14 & 3.27 & 0.67 & 3.8 & 0.64 \\
\hline EBC15 & 2 & 0.7 & 2.3 & \\
\hline EBC16 & 3.61 & 0.74 & 4 & 0.66 \\
\hline EBC17 & 2.35 & 0.81 & 2.43 & 0.73 \\
\hline $\mathrm{EBC} 18$ & 3.08 & 0.7 & 2.74 & 0.6 \\
\hline EBC19 & 3.61 & 0.62 & 3.72 & 0.61 \\
\hline EBC20 & 2.45 & 0.77 & 4.27 & \\
\hline $\mathrm{EBC} 21$ & 2.52 & 0.73 & 3.43 & 0.73 \\
\hline $\mathrm{EBC} 22$ & 2.58 & 0.8 & 3.4 & 0.62 \\
\hline $\mathrm{EBC} 23$ & 2.37 & 0.71 & 3.25 & 0.67 \\
\hline EBC24 & 3.07 & 0.64 & 3.96 & 0.61 \\
\hline $\mathrm{EBC} 25$ & 2.8 & 0.73 & 3.87 & \\
\hline EBC26 & 2.35 & 0.67 & 2.69 & \\
\hline $\mathrm{EBC} 27$ & 3.6 & 0.72 & 3.97 & 0.65 \\
\hline EBC28 & 3.3 & 0.8 & 3.6 & 0.68 \\
\hline EBC29 & 2.8 & 0.73 & 3.72 & 0.64 \\
\hline EBC30 & 3.1 & 0.68 & 2.82 & 0.64 \\
\hline EBC31 & 3.6 & 0.73 & 3.57 & 0.67 \\
\hline EBC32 & 3.42 & 0.73 & 4.04 & 0.69 \\
\hline EBC33 & 3.1 & 0.65 & 2.73 & 0.63 \\
\hline EBC34 & 3.2 & 0.72 & 4.39 & 0.63 \\
\hline EBC35 & 2.94 & 0.7 & 3.26 & \\
\hline EBC36 & 2.9 & 0.71 & 4.12 & 0.63 \\
\hline EBC37 & 2.43 & 0.69 & 3.29 & \\
\hline EBC38 & 2.39 & 0.75 & 2.39 & 0.61 \\
\hline ЕВC39 & & 0.68 & 5.89 & 0.62 \\
\hline
\end{tabular}


Table S2. Summary of blind set prediction results.

\begin{tabular}{|c|c|c|}
\hline id & Real & Pred \\
\hline UK1 & 0 & 0 \\
\hline UK2 & 0 & 1 \\
\hline UK3 & 0 & 0 \\
\hline UK4 & 0 & 1 \\
\hline UK5 & 0 & 0 \\
\hline UK6 & 0 & 0 \\
\hline UK7 & 0 & 0 \\
\hline UK8 & 0 & 0 \\
\hline UK9 & 0 & 0 \\
\hline UK10 & 0 & 0 \\
\hline UK11 & 0 & 0 \\
\hline UK12 & 0 & 0 \\
\hline UK13 & 0 & 0 \\
\hline UK14 & 0 & 0 \\
\hline UK15 & 0 & 0 \\
\hline UK16 & 0 & 0 \\
\hline UK17 & 0 & 0 \\
\hline UK18 & 0 & 0 \\
\hline UK19 & 0 & 0 \\
\hline UK20 & 0 & 0 \\
\hline UK21 & 0 & 0 \\
\hline UK22 & 0 & 0 \\
\hline UK23 & 0 & 0 \\
\hline UK24 & 0 & 0 \\
\hline UK25 & 0 & 0 \\
\hline UK26 & 0 & 0 \\
\hline UK27 & 0 & 0 \\
\hline UK2 8 & 0 & 0 \\
\hline UK29 & 0 & 0 \\
\hline UK30 & 0 & 0 \\
\hline UK31 & 0 & 0 \\
\hline UK32 & 0 & 0 \\
\hline UK33 & 0 & 0 \\
\hline UK34 & 0 & 0 \\
\hline UK35 & 0 & 0 \\
\hline UK36 & 0 & 0 \\
\hline UK37 & 0 & 0 \\
\hline UK38 & 0 & 0 \\
\hline UK39 & 0 & 0 \\
\hline UK40 & 0 & 0 \\
\hline UK41 & 0 & 0 \\
\hline UK42 & 0 & 0 \\
\hline
\end{tabular}




\begin{tabular}{|c|c|c|}
\hline Continued & & \\
\hline UK43 & 0 & 0 \\
\hline UK44 & 0 & 0 \\
\hline UK45 & 0 & 0 \\
\hline UK46 & 0 & 0 \\
\hline UK47 & 0 & 0 \\
\hline UK48 & 0 & 0 \\
\hline UK49 & 0 & 0 \\
\hline UK50 & 0 & 0 \\
\hline UK51 & 0 & 0 \\
\hline UK52 & 0 & 0 \\
\hline UK53 & 0 & 0 \\
\hline UK54 & 0 & 0 \\
\hline UK55 & 0 & 0 \\
\hline UK56 & 0 & 1 \\
\hline UK57 & 0 & 0 \\
\hline UK58 & 0 & 0 \\
\hline UK59 & 0 & 0 \\
\hline UK60 & 0 & 0 \\
\hline UK61 & 0 & 0 \\
\hline UK62 & 0 & 0 \\
\hline UK63 & 0 & 0 \\
\hline UK64 & 0 & 0 \\
\hline UK65 & 0 & 0 \\
\hline UK66 & 0 & 0 \\
\hline UK67 & 0 & 0 \\
\hline UK68 & 0 & 0 \\
\hline UK69 & 0 & 0 \\
\hline UK70 & 0 & 0 \\
\hline UK71 & 0 & 0 \\
\hline UK72 & 0 & 0 \\
\hline UK73 & 0 & 0 \\
\hline UK74 & 0 & 0 \\
\hline UK75 & 0 & 0 \\
\hline UK76 & 0 & 0 \\
\hline UK77 & 0 & 0 \\
\hline UK78 & 0 & 0 \\
\hline UK79 & 0 & 0 \\
\hline UK80 & 0 & 0 \\
\hline UK81 & 0 & 0 \\
\hline UK82 & 0 & 0 \\
\hline UK83 & 0 & 0 \\
\hline UK84 & 0 & 0 \\
\hline UK85 & 0 & 0 \\
\hline
\end{tabular}




\begin{tabular}{|c|c|c|}
\hline Continued & & \\
\hline UK86 & 0 & 0 \\
\hline UK87 & 0 & 0 \\
\hline UK88 & 0 & 1 \\
\hline UK89 & 0 & 0 \\
\hline UK90 & 0 & 0 \\
\hline UK91 & 0 & 0 \\
\hline UK92 & 0 & 0 \\
\hline UK93 & 0 & 0 \\
\hline UK94 & 0 & 0 \\
\hline UK95 & 0 & 0 \\
\hline UK96 & 0 & 0 \\
\hline UK97 & 0 & 1 \\
\hline UK98 & 0 & 0 \\
\hline UK99 & 0 & 0 \\
\hline UK100 & 0 & 0 \\
\hline UK101 & 0 & 0 \\
\hline UK102 & 0 & 0 \\
\hline UK103 & 0 & 0 \\
\hline UK104 & 0 & 0 \\
\hline UK105 & 0 & 0 \\
\hline UK106 & 0 & 0 \\
\hline UK107 & 0 & 0 \\
\hline UK108 & 0 & 0 \\
\hline UK109 & 0 & 0 \\
\hline UK110 & 0 & 0 \\
\hline UK111 & 0 & 0 \\
\hline UK112 & 0 & 0 \\
\hline UK113 & 0 & 0 \\
\hline UK114 & 0 & 0 \\
\hline UK115 & 0 & 0 \\
\hline UK116 & 0 & 0 \\
\hline UK117 & 0 & 0 \\
\hline UK118 & 0 & 0 \\
\hline UK119 & 0 & 0 \\
\hline UK120 & 0 & 0 \\
\hline UK121 & 0 & 0 \\
\hline UK122 & 0 & 0 \\
\hline UK123 & 0 & 0 \\
\hline UK124 & 0 & 0 \\
\hline UK125 & 0 & 0 \\
\hline UK126 & 0 & 0 \\
\hline UK127 & 0 & 0 \\
\hline UK128 & 0 & 0 \\
\hline
\end{tabular}




\begin{tabular}{|c|c|c|}
\hline Continued & & \\
\hline UK129 & 0 & 0 \\
\hline UK130 & 0 & 0 \\
\hline UK131 & 0 & 0 \\
\hline UK132 & 0 & 0 \\
\hline UK133 & 0 & 0 \\
\hline UK134 & 0 & 0 \\
\hline UK135 & 0 & 0 \\
\hline UK136 & 0 & 0 \\
\hline UK137 & 0 & 0 \\
\hline UK138 & 0 & 0 \\
\hline UK139 & 0 & 0 \\
\hline UK140 & 0 & 0 \\
\hline UK141 & 0 & 0 \\
\hline UK142 & 0 & 0 \\
\hline UK143 & 0 & 0 \\
\hline UK144 & 0 & 0 \\
\hline UK145 & 0 & 0 \\
\hline UK146 & 0 & 0 \\
\hline UK147 & 0 & 0 \\
\hline UK148 & 0 & 0 \\
\hline UK149 & 0 & 0 \\
\hline UK150 & 0 & 0 \\
\hline UK151 & 0 & 0 \\
\hline UK152 & 0 & 0 \\
\hline UK153 & 0 & 0 \\
\hline UK154 & 0 & 0 \\
\hline UK155 & 0 & 0 \\
\hline UK156 & 0 & 0 \\
\hline UK157 & 0 & 0 \\
\hline UK158 & 0 & 0 \\
\hline UK159 & 0 & 0 \\
\hline UK160 & 0 & 0 \\
\hline UK161 & 0 & 0 \\
\hline UK162 & 0 & 0 \\
\hline UK163 & 0 & 0 \\
\hline UK164 & 0 & 0 \\
\hline UK165 & 0 & 0 \\
\hline UK166 & 1 & 1 \\
\hline UK167 & 1 & 1 \\
\hline UK168 & 1 & 0 \\
\hline UK169 & 1 & 1 \\
\hline UK170 & 1 & 0 \\
\hline UK171 & 1 & 1 \\
\hline
\end{tabular}




\begin{tabular}{|c|c|c|}
\hline Continued & & \\
\hline UK172 & 1 & 0 \\
\hline UK173 & 1 & 1 \\
\hline UK174 & 1 & 1 \\
\hline UK175 & 1 & 1 \\
\hline UK176 & 1 & 1 \\
\hline UK177 & 1 & 1 \\
\hline UK178 & 1 & 1 \\
\hline UK179 & 1 & 1 \\
\hline UK180 & 1 & 1 \\
\hline UK181 & 1 & 0 \\
\hline UK182 & 1 & 1 \\
\hline UK183 & 1 & 1 \\
\hline UK184 & 1 & 1 \\
\hline UK185 & 1 & 1 \\
\hline UK186 & 1 & 1 \\
\hline UK187 & 1 & 0 \\
\hline UK188 & 1 & 0 \\
\hline UK189 & 1 & 1 \\
\hline UK190 & 1 & 1 \\
\hline UK191 & 1 & 0 \\
\hline UK192 & 1 & 1 \\
\hline UK193 & 1 & 0 \\
\hline UK194 & 1 & 1 \\
\hline UK195 & 1 & 1 \\
\hline UK196 & 1 & 1 \\
\hline UK197 & 1 & 1 \\
\hline UK198 & 1 & 1 \\
\hline UK199 & 1 & 0 \\
\hline UK200 & 1 & 1 \\
\hline UK201 & 1 & 0 \\
\hline UK202 & 1 & 0 \\
\hline UK203 & 1 & 0 \\
\hline UK204 & 1 & 1 \\
\hline UK205 & 1 & 1 \\
\hline UK206 & 1 & 1 \\
\hline UK207 & 1 & 1 \\
\hline UK208 & 1 & 0 \\
\hline UK209 & 1 & 1 \\
\hline UK210 & 1 & 1 \\
\hline UK211 & 1 & 0 \\
\hline UK212 & 1 & 0 \\
\hline UK213 & 1 & 0 \\
\hline UK214 & 1 & 0 \\
\hline
\end{tabular}




\begin{tabular}{|c|c|c|}
\hline Continued & & \\
\hline UK215 & 1 & 1 \\
\hline UK216 & 1 & 1 \\
\hline UK217 & 1 & 0 \\
\hline UK218 & 1 & 1 \\
\hline UK219 & 1 & 0 \\
\hline UK220 & 1 & 0 \\
\hline UK221 & 1 & 1 \\
\hline UK222 & 1 & 0 \\
\hline UK223 & 1 & 1 \\
\hline UK224 & 1 & 1 \\
\hline UK225 & 1 & 1 \\
\hline UK226 & 1 & 1 \\
\hline UK227 & 1 & 1 \\
\hline UK228 & 1 & 0 \\
\hline UK229 & 1 & 1 \\
\hline UK230 & 1 & 0 \\
\hline UK231 & 1 & 1 \\
\hline UK232 & 1 & 1 \\
\hline UK233 & 1 & 1 \\
\hline UK234 & 1 & 1 \\
\hline UK235 & 1 & 1 \\
\hline UK236 & 1 & 1 \\
\hline UK237 & 1 & 1 \\
\hline UK238 & 1 & 1 \\
\hline UK239 & 1 & 1 \\
\hline UK240 & 1 & 1 \\
\hline UK241 & 1 & 1 \\
\hline UK242 & 1 & 1 \\
\hline UK243 & 1 & 1 \\
\hline UK244 & 1 & 0 \\
\hline UK245 & 1 & 1 \\
\hline UK246 & 1 & 1 \\
\hline UK247 & 1 & 1 \\
\hline UK248 & 1 & 0 \\
\hline UK249 & 1 & 0 \\
\hline UK250 & 1 & 1 \\
\hline UK251 & 1 & 1 \\
\hline UK252 & 1 & 1 \\
\hline UK253 & 1 & 0 \\
\hline UK254 & 1 & 0 \\
\hline UK255 & 1 & 1 \\
\hline UK256 & 1 & 0 \\
\hline UK257 & 1 & 1 \\
\hline
\end{tabular}




\begin{tabular}{|c|c|c|}
\hline \multicolumn{3}{|l|}{ Continued } \\
\hline UK258 & 1 & 1 \\
\hline UK259 & 1 & 1 \\
\hline UK260 & 1 & 1 \\
\hline UK261 & 1 & 1 \\
\hline UK262 & 1 & 1 \\
\hline UK263 & 1 & 1 \\
\hline UK264 & 1 & 1 \\
\hline UK265 & 1 & 0 \\
\hline UK266 & 1 & 1 \\
\hline UK267 & 1 & 1 \\
\hline UK268 & 1 & 1 \\
\hline UK269 & 1 & 0 \\
\hline UK270 & 1 & 1 \\
\hline UK271 & 1 & 1 \\
\hline UK272 & 1 & 1 \\
\hline UK273 & 1 & 1 \\
\hline UK274 & 1 & 1 \\
\hline UK275 & 1 & 0 \\
\hline UK276 & 1 & 1 \\
\hline UK277 & 1 & 0 \\
\hline UK278 & 1 & 0 \\
\hline UK279 & 1 & 0 \\
\hline UK280 & 1 & 0 \\
\hline UK281 & 1 & 1 \\
\hline UK282 & 1 & 1 \\
\hline UK283 & 1 & 0 \\
\hline UK284 & 1 & 0 \\
\hline \multirow[t]{2}{*}{ UK285 } & 1 & 1 \\
\hline & True & False \\
\hline type 0 & 160 & 5 \\
\hline type 1 & 32 & 82 \\
\hline
\end{tabular}


Scientific Research Publishing (SCIRP) is one of the largest Open Access journal publishers. It is currently publishing more than 200 open access, online, peer-reviewed journals covering a wide range of academic disciplines. SCIRP serves the worldwide academic communities and contributes to the progress and application of science with its publication.

Other selected journals from SCIRP are listed as below. Submit your manuscript to us via either submit@scirp.org or Online Submission Portal.
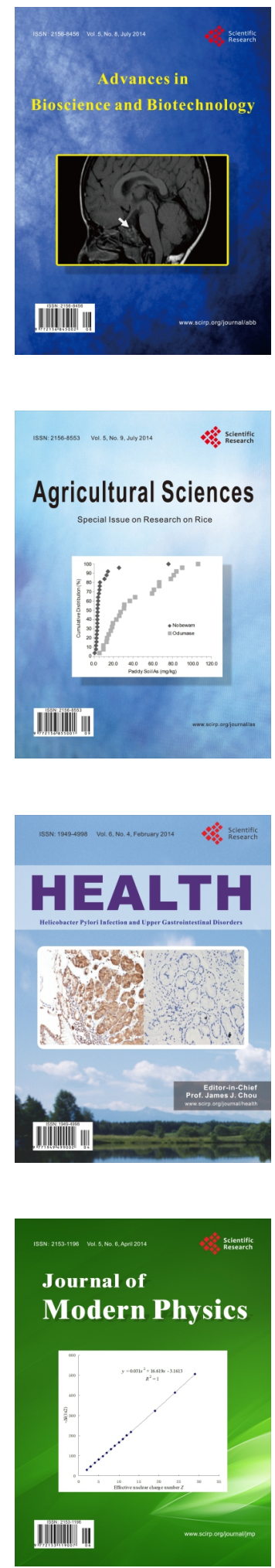
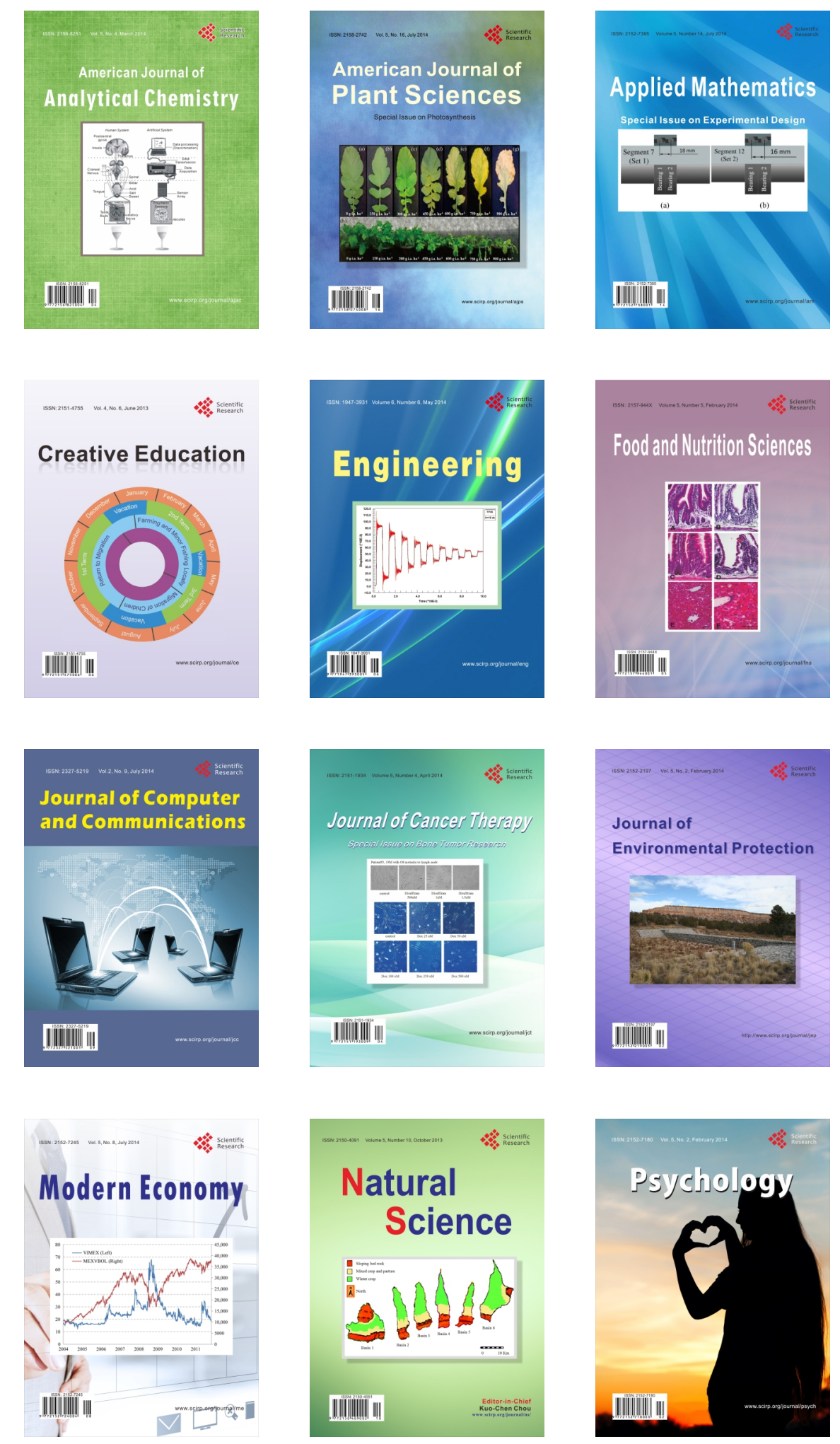